\title{
História Conceitual: sentidos da modernidade hispano-americana
}

\author{
Mariana Ferraz Paulino \\ Mestranda em História Social (USP) \\ E-mail: mariana_ferraz_paulino@hotmail.com
}

Resenha de:ZERMEÑO PADILLA, Guillermo. Historias Conceptuales. Ciudad de México: El Colegio de México/Centro de Estudios Históricos, 2017.

Com um título que reitera as contribuições do historiador mexicanoGuillermoZermeñoPadillaparaosestudosdaslinguagens políticas nasúltimasdécadas, aobraHistoriasConceptualesreúneumconjuntode dezartigos originalmente publicados de 2005 a 2014 que, apresentados em versões modificadas, encerram, de acordo com o autor, um ciclo deinvestigações dedicadoà crítica histórica baseada em análises de conceitos. Sendo uma "obra aberta", na medida em que não pretende explorar exaustivamente cada um dos assuntos tratados, mas simmostrartraçosessenciaisdoprocesso detransformaçãoesedimentaçãodecertaspalavrasem conceitosmodernos, HistoriasConceptuales revelacomodiversosvocábuloseconceitoscomumenteutilizadosem descriçõeshistóricasesociológicassão,emseucerne, invenções, transformações, ressignificaçõesoureapropriaçõeslinguísticasdachamada "modernidade" -entidade semântica discutida pelo historiador na introdução de sua obra.

Em “El 'espacio público' como concepto histórico: Habermas y la nueva história política", Zermeño Padilla recria o contexto histórico-filosófico do projeto habermasiano, discutindo sua penetração na dimensão historiográfica hispano-americana e enfatizando suascontribuições para a obra de François-Xavier Guerra. Percorrendo especialmente o conceito de "público" ou "espaço público", o autor aborda oimpactodomodelodeJürgen HabermasnaobracoletivaLosespacios 
públicosen Iberoamerica(1998),coordenadaporGuerraeAnnickLempérière. Aofazê-lo, Zermeño Padilla pontua apropriações da tipologia habermasiana - como a utilização do conceito de "espaço público" para esclarecer as peculiaridades da incorporação dos países iberoamericanos à modernidade (p.51) -, bem como críticas a essa tipologia - dentre outras, as dificuldades em descobrir a formação de um espaço burguês deopinião pública na gênese das nações iberoamericanas (p.55).ZermeñoPadillainclui,também,consideraçõesdeespecialistas europeus sobre a obra de Habermas, em particular a periodização por ele estabelecida, o emprego de um modelo marxista convencional ea conotação teleológica inerente ao termo"burguês". Zermeño conclui o capítulo indicando que o espaço público não deve ser reduzido à opinião pública, e que o distintivo desta modernidade a que se referem Habermas e Guerra consiste no privilégio que ela confere ao âmbito da escrita e a suas formas de circulação, viabilizadas pela liberdade de imprensa e pela materialidade do impresso (p.62). Clamando pela tradição como principal sustento da modernidade e por uma reformulação desse conceito, Zermeño Padilla sugere que é preciso compreendê-locomoumconceitodetemporalidade,semconfundi-la com o que pode ser uma forma "aparente" de modernidade (p.65).

Em “De la historia como un arte a la historia como una ciencia”, o autor discute a transformação semântica da voz "história" no período de transição do regime político e intelectual da Nova Espanha para o mexicano ou republicano (p.67). Ao montar seu argumento, Zermeño Padilla parte da distinção entre "voz" e "palavra", bem como de alguns preceitos de ReinhartKoselleckquantoà conjunção das histórias sincrônica e diacrônica na segunda metade do século XVIII, quando umnovosentidodetemporalidadeatravessou ovocabuláriopolíticoe social da época (p.69). Percorrendo as diversas instâncias deressignificação conceitual e epistemológica de"história", Zermeño evoca o período em que esta era concebida fundamentalmente como"um saber dirigido a entreter, instruir e ilustrar"(p.75), uma "arte" a ser ensinada eaprendida mediante métodos instruídos, como se vê nas Gacetas do México e nos escritos de José Ignacio Bartolache, José Antonio Alzate y Ramírez e Francisco Xavier Clavijero. O autor trata, ainda, do 
processo de politização da voz "história", bem como da consagração do neologismo "história contemporânea", processo no qual "história" se tornou entidade filosófica e científica, passível de incorporação aos processosdelndependênciaeàsposterioresdiscussõessobreostrezentos anos de opressão colonizadora espanhola.

No seguinte artigo, "Los usos políticos de América/americanos (1750 - 1850)", Zermeño Padilla refaz a trajetória das vozes que dão títuloaotexto,centrando-senoperíodocompreendidoentreacrisedo Antigo Regime e a emergência de formas constitucionais das nações modernas.Procedendodepublicaçõesperiódicas comofontes primárias, o historiador contempla os distintos estágios de transformação semântica das vozes "América" e "americanos". De acordo com o autor, o período entre 1750 e 1850 permite vislumbrar uma progressão semânticaqueatravessaosdoistermos, percursoquevaidogeográfico ao político e que retorna do político ao cultural como resultado da impossibilidade de conformar uma unidade política continental após as emancipações (p.147). Para tanto, Zermeño Padilla trata da possível percepção de certo sentido de orfandade e isolamento por parte dos habitantes da geografia americana em relação à Espanha nas três primeiras décadas do século XIX, o que teria ocorrido em concomitância com o desenvolvimento de um sentimento nacionalista não mais fundadonocontrastesecularentreamericanose europeus, massimna contraposição das nações americanasentre si, num contextodeautorreivindicações das identidades nacionais emergentes.

O texto seguinte, escrito em co-autoria com Peer Schmidt, se intitula "De las 'libertades' a la Libertad". Segundo Zermeño e Schmidt, osentidodaspalavrasmudaconformeosespaçosdeexperiência oude contato comunicativo em que se inserem. Dessa maneira, o vocábulo liberdadenãopossuiamesma conotaçãoseaplicadoaumcontextoprisional (em que o indivíduoécastigadocoma privação daliberdade) ou a um contexto de escravidão (no qual se anula o direito de ser livre por meio de uma obrigação laboral imposta) (p.149). Centrando suas análises no longo século XIX, os autores tratam dos vários sentidos que o termo e alguns vocábulos dele derivados, como "livre", "libertador" ou "liberal", possuíra no longo século XIX. As situações analisadas são 
diversas: desde que Miguel Hidalgo y Costilla utilizara a expressão"liberdade política" em 1810, passando pela reivindicação da liberdade de imprensa e opinião presentes no texto do Decreto Constitucional para la Libertad de la América mexicana, sancionado em Apatzingán em outubro de 1814, até o episódio em que o jovem general Porfírio Díaz, combatente das forças antiimperialistas, levantou-se em armas contra Benito Juárez e exigiu respeito à "la libertad del sufragio popular" em 1871, bem como quando em 1910 Francisco Madero empreendera, em nome da "libertad electoral", a deposição do mesmo Porfírio Díaz da Presidência do México. Evidentemente, Hidalgo y Costilla, o Decreto de Apatzingán, Porfírio Díaz e Francisco Madero - bem como as outras personagens do capítulo - não estão tratando da mesma "liberdade", uma vez que cada uma das vozes evocadas, representadaspelomesmosignoterminológicomasnãosendojamais amesmavoz,sofreudiversastransformaçõessemânticasduranteolongo século XIX mexicano.

Em "De las 'revoluciones' a la Revolución", Zermeño Padilla se pauta nas "consequências sistêmicas" da Revolução Francesa para tratar dos efeitos linguísticos da crise de 1808 no território da Nova Espanha. Partindo do chamado Grito de Dolores de 1810, cujo adensamento semântico fora amparado pelo estabelecimento da Constituição de Cádiz, o historiador percorre as diversas instâncias de apropriação, adequação, desvalorização ou ressignificação em que se inscreveu o termo "revolução" ao longo do século XIX mexicano. Zermeño Padilla menciona aqui diversas contribuições epistemológicas, tais como a de Carlos María de Bustamante, cronista cujo “Diario histórico de México" fora escrito num período de depreciação do termo; de José María Luís Mora, que inserido no contexto de 1836 alegava que até o conquistador Hernán Cortés deveria ser considerado precursor da luta da Nova Espanha por sua independência (p.184); e de Lorenzo de Zavala, para quem o termo "revolução" implicava uma noção de temporalidade consciente que segregava a História em dois momentos cuja dobradiça era o ano de 1808. 0 historiador conclui o sexto capítulo da obra sugerindo que a Revolução de Ayutla e a nova Constituição de 1857 teriam encerrado o ciclo revolucionário mexicano inaugurado em 1808, e que um novo 
ciclo se iniciaria em 1876 com a expedição do Plan de Tuxtepec por Porfírio Díaz.

De acordo com Zermeño, "civilização" é um neologismo setecentista legado do francês e não se encontra em léxicos anteriores a 1780 (p.193). A partir daí, o autor acompanha a trajetória do vocábulo, tratando de sua estabilização como conceito eabordando as transformações semânticas que o permearam no século XIX, contemplando não apenas o contexto da Nova Espanha e do México, mas também a dimensão peruana no subitem "Emancipación y Dilemas Políticos". Ao longo do capítulo, Zermeño trata de uma primeira mutação sofrida pelo vocábulo, entre a Revolução Francesa e o período napoleônico, perseguindoseusvestígiossemânticosemcircunstânciaspautadaspor temas como liberalismo e ilustração, a própria concepção de "civilização moderna", a questão das subalternidades, e as discussões referentes a sua associação aos termos "ordem" e "progresso" nas últimas décadas do XIX.

"Pobreza: historia de un concepto" é o mais dissonante dos capítulos no que diz respeito ao recorte temporal da obra. Isso porque Zermeño escapa ao chamado"umbral clássico da história conceitual" (1750 a 1850) e estuda a genealogia da voza partir de indícios legados pela Antiguidade Cristã e Medieval, bem como por noções elaboradas no seio do cristianismo primitivo. Considerando que a partir da segundametadedossetecentosapobrezadesgarrou-sepaulatinamente da carga religiosa que sempre a engendrara, Zermeño aborda temas como mendicância, esmola, indigência, até situar a voz como problema de Estado e discutir algumas de suas implicações no léxico contemporâneo. Objetivando "desnaturalizar" a noção de "pobreza", o historiador alega que mesmo quando a voz se manteve associada a seu sentido comum e geral - que designa uma situação de carência ou incapacidades básicas (p.213) -, sua semântica foi modelada por diversas operações de incorporação ou descartes de sentidos. Tanto o que se incorporou quanto o que se descartou iluminama utilização do conceito nos dias de hoje.

Em “Del mestizo al mestizaje: arqueología de un concepto”, Zermeño Padilla trata da aparição histórica da mestiçagem como uma noção que "aspira a descrever a identidade nacional do México" 
(p.261). Sua hipótese é de que "a invenção da mestiçagem como princípio regulador da identidade nacional moderna [mexicana] teve um efeito negativo (no nível das representações) em relação à população 'indígena' (denominada assim a partir do século XIX)" (p.263). Situando leitores e leitoras em relação a diversas figuras relevantes para a compreensão tanto do fenômeno como do processo histórico mais amplo, Guillermo Zermeño atribui a José Vasconcelos a competência de ter convertido uma noção singular sociológica ("mestiço") em um conceito universal de caráter filosófico ("mestiçagem") (p.266), destacando neste decurso a importância da Revolução de Ayutla e do triunfo da reforma de Benito Juárez para a transição de uma a outro - processo que culmina com a celebração do chamado Día de la Raza em 12 de Outubro de 1917. A conversão de "mestiço" a "mestiçagem" encabeçada por Vasconcelos teria, de acordo com Zermeño, inserido o debate numa pauta biologicista da evolução humana, o que leva o autor a reivindicar que um dos aspectos mais problemáticos no estabelecimento do conceito "mestiçagem" esteja no fato de que sua construção tenha se dado com base na subjugação e desvalorização das populações indígenas.

No capítulo sobre os conceitos de "cacique", "caciquismo" e "caudillismo", o penúltimo da obra, Guillermo Zermeño percorre o legado histórico-semântico do termo "cacique" e de seus derivados, tomado originalmente das línguas caribenhas e empregado inicialmente no contexto do Império espanhol para designar "certas formas político-administrativas e certos intermediários entre o poder espanhol e as populações indianas" (p.298). No artigo, Zermeño mostra como a reinvenção dos termos - atentando-se de modo menos enfático a "caudillismo", o que traz certa carência à totalidade da proposta do capítulo - se forjou em contextos específicos. Uma de suas intenções aqui, com base na aparição e evolução do termo na imprensa mexicana ao longo dos séculos XIX e XX, é esclarecer por quais razões e de que modo o termo "cacique" se transformou numa instância catalisadora das múltiplas características do regime político mexicano (p.317).

O último capítulo de Guillermo Zermeño Padilla intitula-se "La invención del intelectual y su crisis". Dada a amplitude do tema, o historiador contempla a formação do campo intelectual no Méxi- 
co do século XX, partindo da premissa geral de que o Antigo Regime pré-industrial hispano-americano, com ou sem revolução social, teria gerado as condições necessárias para o desenvolvimento de um novo tipo de "sábio" definido pela criação de um espaço comunicativo específico. Considerando as contribuições de figuras tais como Henríquez Ureña, Alfonso Reyes, Gómez Morin, José Vasconcelos e Octavio Paz, o historiador trata da paulatina consumação identitária do intelectual em âmbito mexicano, explicitando algumas das diferenças entre a mencionada geração e a anterior. Para Zermeño, assim como o período pré-industrial teria outorgado aos "filósofos" positivistas - no caso mexicano, chamados "científicos" - o papel de "questionar o velho inventário do saber coletivo", o século XX teria delegado à figura do "intelectual" mexicano a missão de conformar um novo saber crítico que estivesse consciente de sua capacidade de imiscuir-se na História (p.325).

Além de confirmar as fecundas colaborações de Guillermo Zermeño Padilla para o campo investigativo das linguagens políticas, Historias Conceptuales convida-nos a refletir, enhorabuena, sobre algumas das instâncias que engendram as experiências discursivas ao longo da história, propondo aos leitores e leitoras uma série de percursos fundamentais acerca dos vocábulos e conceitos em distintos cenários da modernidade. Se, de acordo com Zermeño, "a história conceitual é apenas a porta de entrada para questões apaixonantes acerca do significado e do sentido que existe em escrever histórias no umbral mutante em que nos encontramos na atualidade, relacionado com a crise do tempo histórico especificamente moderno" (p.20), Historias Conceptuales cumpre o papel de bússola no âmago deste umbral, que, apesar de permeado por múltiplos desafios, pode ser traduzido e decodificado na medida em que nos empoderamos, especialmente como historiadores e historiadoras, do magistral artifício político que é a consciência histórica da e sobre a linguagem.

Recebido: 03/01/2018 - Aprovado: 30/03/2018

Referência

ZERMEÑO PADILLA, Guillermo. Historias Conceptuales. Ciudad de México: El Colegio de México/Centro de Estudios Históricos, 2017. 